\title{
Que Destino Dar À Mensagem ReCEBIDA? APONTAMENTOS SOBRE A QUESTÃO DA TRANSMISSÃO NA PSICANÁLISE
}

\author{
Ana Laura Prates \\ Instituto de Psicologia - USP
}

\begin{abstract}
Este artigo apresenta a especificidade do conceito de transmissão na Psicanálise, sobretudo a partir da proposição de Jacques Lacan segundo a qual "o inconsciente é estruturado como uma linguagem". Desenvolve a idéia apresentada por esse autor, nos anos cinqüenta, de que a constituição subjetiva humana resulta de uma experiência de transmissão da lei simbólica através da mediação paterna, o que se desdobrará nos conceitos de Metáfora paterna e Nome-do-Pai. Analisa as conseqüências teórico-clínicas promovidas pelo conceito de objeto a para a questão da transmissão, sobretudo no que diz respeito ao gozo fora da linguagem e à montagem fantasmática. Aponta ainda para o avanço significativo que $\mathrm{O}$ Seminário - O Avesso da Psicanálise oferece no que se refere àquilo que se transmite para além do simbólico, a partir da articulação da noção conceitual de discurso sem palavras e da impotência do saber em abarcar toda a verdade. Finalmente, propõe que a idéia de "potência de criação" substitui aquela de "pai potente" dos anos cinqüenta, revelando desdobramentos clínicos para o debate sobre o final de uma análise.
\end{abstract}

Descritores: Psicanálise. Transmissão. Metáfora. Gozo. Lacan, Jacques, 1901-1981.

1 Doutoranda em Psicologia Clínica pelo Instituto de Psicologia - USP. Psicanalista, membro da Escola de Psicanálise dos Fóruns do Campo Lacaniano - Brasil, Fórum São Paulo. Endereço de correspondência: Rua Joaquim Floriano, 101 - cj 403 Itaim Bibi. Endereço eletrônico: analaura@ hydra.com.br 


\title{
1. A Herança simbólica
}

\begin{abstract}
Não que a experiência vivida seja indizível. Ela foi invivivel, o que é outra coisa. Outra coisa que não se refere à forma de um relato possivel, mas à sua substância. Não à sua articulação, mas à sua densidade. Só alcançarão essa substância, essa densidade transparente os que souberem fazer de seu testemunho um objeto artístico, um espaço de criação. Ou de recriação. Só o artifício de um relato que se possa controlar conseguirá transmitir parcialmente a verdade do testemunho (Semprún, 1995)
\end{abstract}

ob certo ângulo, não seria exagerado afirmar que a possibilidade de uma transmissão, além daquela que se dá através da hereditariedade genética, é o que confere à dimensão humana sua especificidade. A artificialidade da norma social, na medida em que nos afasta da natureza, só é possível de ser sustentada a partir do fato de que algo pode ser passado, transmitido por meio das gerações. Assim, o conjunto de criações humanas que chamamos de cultura pode ser pensado como uma herança simbólica e, nesse contexto, fica evidente o papel crucial que a linguagem exerce na especificação do que significa sermos humanos. O fato de que não há ser humano fora da linguagem revela, por um lado, seu caráter fundante de um outro nível de relações - mediadas, como diria Vygotsky -, para além daquelas existentes entre organismos e meio ambiente. Por outro lado, a própria linguagem que se transmite é, por sua vez, o meio de transmissão, o que fica muito evidente nos trabalhos de Lévi-Strauss a respeito das estruturas elementares de parentesco, onde também se esclarece a função do sobrenome no sentido de marcar um lugar simbólico e sexual na estrutura familiar e social.

Em relação à função de transmissão inerente à linguagem, é bastante relevante a distinção feita por Saussure entre língua e fala, pois, se por um 
lado temos a língua como aquilo que "já está dado", ou seja, algo que cada novo indivíduo recebe pronto ao nascer; por outro lado, a fala, sendo a vertente individual da linguagem, inclui aí a dimensão da criação desse indivíduo, na medida em que ele tem o poder de criar a partir do código estabelecido, ao qual deve se submeter para se fazer compreender por seus pares. A dimensão da fala, entretanto, afeta aquela da língua, transformando-a continuamente. Nota-se, aí, uma interessante relação entre o universal representado pela língua e o particular da fala que coloca, de entrada, uma das questões que tenho trabalhado em minha pesquisa atual: o que cada um faz com sua herança simbólica? Qual é a nossa "margem de liberdade"?

A partir da Psicanálise, entretanto - notadamente da leitura de Freud operada por Lacan -, podemos ter acesso a um outro nível de transmissão, para além daquele mencionado anteriormente. Preliminarmente, digamos que, através da linguagem, o inconsciente passa. Ou seja, o inconsciente não é um objeto, ou um fato orgânico. Tampouco seria algo das profundezas da mente: o inconsciente está na superfície - estruturado como uma linguagem, ou seja, segundo a estrutura da metáfora e da metonímia. Dizer que o inconsciente passa, exige, logicamente, a presença do Outro enquanto lugar de endereçamento da mensagem. Não há inconsciente sem Outro: o inconsciente é o discurso do Outro. A própria descoberta do inconsciente só foi possível graças ao gênio de Freud que, subvertendo a clínica médica, propôs-se a escutar o que a histérica tinha a dizer sobre seu sintoma, abrindo, desse modo, as portas para que o desejo pudesse aparecer. Fale mais sobre isso! - esse único imperativo da psicanálise que define a regra fundamental da associação livre - é, de certa forma, um convite à transmissão que o analista faz ao analisante: fale mais, fale melhor, fale outra vez, lembre outra cena, conte de novo aquela história... No entanto, é nos tropeços que "algo" da verdade do sujeito passa, através ou apesar da enunciação. No tropeço, no erro, ou seja: nos atos falhos, nos lapsos, nos esquecimentos, nos sintomas que incomodam, nos sonhos desconcertantes e em tudo aquilo que Freud chamava de formações do inconsciente. Em psicanálise, entretanto, de nada vale um sintoma, um sonho, um ato - mesmo que falho - se não passar pelo desfile dos significantes. O sintoma, nesse sentido, só é formação do inconsciente 
se puder ser tomado enquanto mensagem dirigida ao Outro, o que quer dizer que, rigorosamente, o inconsciente é sempre uma hipótese a ser testada, sob transferência, no artifício do dispositivo analítico. Isso não significa, entretanto, que o inconsciente seja inefável ${ }^{2}$ ou intransmissível; ao contrário, bcalizá-lo no nível da linguagem possibilita a formalização de sua lógica peculiar, o que apenas faz aumentar a exigência em relação àqueles que o experimentam e que, a partir daí, devem dar as provas de sua existência.

Poderíamos dizer que a psicanálise seria, então, uma experiência de transmissão, na qual o sujeito, supondo carregar sua herança simbólica, como enviado do outro, vai aos poucos, ele mesmo, escrevendo sua própria mensagem, ainda que de forma invertida?

\section{O destino da mensagem}

Transmissão: passagem de um lugar para outro, trajeto.

Transmitir: passar a outrem, destinar para, enviar, comunicar por contágio.

(Houaiss , 2001, p. 2752)

Uma das definições possíveis da palavra transmissão, na língua portuguesa, nos remete à questão topológica, ou seja, de algo que passa de um lugar para outro. $\mathrm{O}$ verbo transmitir, por sua vez, além de reforçar o sentido de "passagem", ainda indica - no sentido do "envio" - a relação da transmissão com a mensagem. Será que, quando se trata da constituição de um sujeito, a carta sempre chega a seu destino? Como se recebe o Nome-do-Pai essa passagem/bilhete que dá acesso ao simbólico?

Lacan já vinha tratando essa questão desde o Seminário 4 - A Relação de Objeto, onde diz, a respeito da função normativa do Complexo de Édipo,

2 Sobre isso, ver o que diz Lacan na "Ata de fundação da EFP”, de 21/06/64, na "Seção de inventário do campo freudiano". 
Que Destino Dar à Mensagem Recebida? Apontamentos sobre a Questão da...

que não basta que ele conduza a uma escolha objetal heterossexual, mas, além disso, é preciso situar-se corretamente com relação à função do pai. Mais à frente, ele diz que tudo que se passa nas neuroses é feito para suprir uma dificuldade, até mesmo uma insuficiência na maneira como a criança lidou com o Édipo (Lacan, 1956-1957/1999, p. 206). Podemos dizer, então, que para o Lacan do final dos anos 50, a neurose é uma suplência à insuficiência paterna. Há a clara expectativa de que esse pai cumpra plenamente sua função de doador do objeto simbólico, mesmo que ele, às vezes, falhe. "O Caso Hans" é chamado como exemplo dessa fórmula: "o objeto fóbico é o elemento em torno do qual vão guiar as significações que formarão uma suplência ao que faltou o desenvolvimento do sujeito, ou seja, tem uma função de metáfora" (Lacan, 1956-1957/1999, p. 411).

Mas é no ano seguinte, no Seminário dedicado às formações do inconsciente, que o conceito de metáfora paterna ganha consistência: a metáfora do Nome-do-Pai explica como o pai torna-se portador da lei. Ela é a metáfora que substitui este Nome no lugar propriamente simbolizado pela operação da ausência da mãe: "Cada um dos termos é cuidadosamente pesado. O Nome não substitui o desejo da mãe, mas um lugar. Este lugar tem que, ele próprio, ter sido primeiramente simbolizado" (Porge, 1989/1994, p. 40). Vejamos, então, como Lacan articula essa "passagem de lugar" - e, portanto, essa transmissão - que a metáfora paterna opera.

Colocar a função do pai no nível da metáfora implica uma referência a um "passo de sentido" ou, como diz Lacan em relação ao chiste - que remete também à dimensão da metáfora -, "a dimensão para além do significante como aquilo através do qual vocês procuram expressar alguma coisa, e através do qual, apesar de tudo, expressam sempre uma coisa diferente" (Lacan, 1957-1958, 1999, p. 156). Portanto, sendo da ordem da metáfora, o pai é um significante que substitui outro significante, ou, em outras palavras, o pai vem no lugar da mãe. O que isso quer dizer?

É muito interessante notar que, no Seminário 5, Lacan (19571958/1999) articula o pai enquanto mediador, quer dizer, a lei em si já está dada "no mundo" antes dele. É nesse sentido que se pode entender o que 
Lacan chama de "lei materna", na medida em que a mãe é um ser falante. A criança está, então, num primeiro momento, assujeitada ao "capricho artic ulado" do Outro materno, que, entretanto, no vai-e-vem do par presençaausência já torna possível a transmissão preliminar de um lugar - fálico - em relação ao qual a criança possa estabelecer uma primeira e fundante identificação. Ocorre que ocupar esse lugar de suposto objeto de desejo da mãe é necessário, mas está longe de ser suficiente para constituir um sujeito.

Assim, um novo passo se impõe e é aí que entra a mediação: para que a criança possa atingir o "para-além" do desejo do Outro, faz-se necessária essa mediação realizada pela posição paterna na ordem simbólica. A lei deve passar pelo pai, ou, como diz Lacan: "a demanda endereçada ao Outro, caso transmitida como convém, será encaminhada a um tribunal superior" (Lacan, 1957-1958/1999, p. 198, grifos meus). Ou seja, se, por um lado, o pai enquanto mediador transmite a lei que está "no mundo" para o sujeito, por outro lado, é a mãe quem encaminha a mensagem que lhe é dirigida ao "tribunal superior" que o pai representa. Daí compreender a posição do pai do segundo tempo do Édipo como a "presença privadora", na medida em que se oferece enquanto o suporte, ou melhor, como "portador" da lei.

O próximo passo implica propriamente numa passagem, uma transmissão no sentido literal (como vimos no dicionário), pois a lei que estava $a$ priori "no mundo" e da qual o pai é agora o portador, deverá ser incluída no campo do Outro, como esclarece Antônio Quinet:

A inclusão do significante do Nome-do-Pai no Outro marca, portanto, a entrada do sujeito na ordem simbólica e permite a inauguração da cadeia do significante no inconsciente, implicando as questões do sexo e da existência, questões fechadas ao sujeito neurótico. (Quinet, 1997, p. 13)

O pai desse terceiro tempo, que é aquele da castração, é conceituado nesse momento do ensino de Lacan como "pai potente", ou seja, "que é capaz de dar à mãe o que ela deseja e pode dar porque o possui" (Lacan, 19571958/1999, p. 200). 
Se observarmos a fórmula da metáfora paterna, tal como Lacan (19551956/1998) a apresenta no texto "De uma questão preliminar a todo tratamento possível da psicose", vemos que aquilo que o pai potente tem, e passa, é o falo - enquanto significação possível para o significante da falta do Outro $[\mathrm{S}(\mathrm{A})]$.

$$
\frac{N P}{D M} \cdot \frac{D M}{x} \rightarrow N P \frac{A}{\Phi}
$$

Figura 1: Fórmula da metáfora paterna.

Ou seja, o falo do qual o pai é portador fará uma suplência simbólica à falta representada pelo enigma (x) do desejo da mãe. Nesse momento da teoria, é a mãe desejante de falo (uma mãe histérica, por assim dizer) que instaura o pai real como agente da castração. Assim, retomando os comentários que fiz sobre o Seminário 4, eu diria que o que "passa" na metáfora paterna é a significação fálica, como no "passo de sentido", quando Lacan se refere ao chiste.

Entretanto, se cabe ao pai transmitir o falo simbólico enquanto o que faz suplência à falta de objeto do desejo, cabe ao sujeito recebê-lo . Quanto a isso, Lacan é bem claro:

vocês sempre constatarão, na experiência, que o sujeito posicionou-se de uma certa maneira, num momento de sua infância, quanto ao papel desempenhado pelo pai no fato de a mãe não ter o falo. [Ou ainda, em relação ao segundo tempo do Édipo] (...) A frase a ser atravessada coloca o sujeito na situação de escolher. Ponham também esse escolher entre aspas, porque o sujeito é tão passivo quanto ativo nisso, pela simples razão de que não é ele quem manipula as cordinhas do simbólico. A frase foi começada antes dele, foi começada por seus pais. (Lacan, 19571958/1999, pp. 191-192)

O que implica, portanto, esse consentimento do sujeito em receber a lei do pai?

A clínica nos demonstra, em nosso cotidiano, que é essa a questão com a qual o neurótico tem que se haver em seu processo de análise, ou seja, 
que ele não tem escolha, a não ser a de responder pela frase que começou antes dele e, quem sabe, poder escrevê-la com uma pontuação inédita.

Outro ponto bastante interessante - a respeito do qual a psicanálise, por não ser uma ciência do comportamento não deve, entretanto, se furtar a responder - refere-se à importância de sermos precisos quanto à ordem dessa transmissão. Lacan é bastante explícito, no Seminário 5, quanto ao fato de que a função paterna não se exerce no nível do comportamento, ou da presença ou não do pai. A título de ilustração, trarei um exemplo que me colocou diante dessa necessidade de precisão - e que, de resto, traz também um desdobramento desse tema da transmissão num outro enfoque, ou seja, o da possibilidade (ou não) de transmitir a própria psicanálise para além da experiência.

No Centro Universitário onde leciono, fui procurada por um grupo de alunas do curso de Fonoaudiologia que iriam apresentar um caso clínico, cuja queixa referia-se a um atraso significativo no processo de aquisição da linguagem. O histórico da anamnese desse caso apresentou alguns problemas às alunas. Ele era o quarto filho do casal, sendo que o terceiro do sexo masculino. Seu nascimento foi prematuro e, por isso, ele ficou um mês na maternidade até poder ir para casa. Quando, finalmente, teve alta, sua mãe pegou uma pneumonia e teve que ser internada, também durante um período longo, durante o qual o menino foi cuidado pelos avós paternos. Acontece que, durante esse período, foi descoberto um câncer nesse avô e, quando finalmente a mãe teve alta do hospital, os pais ficaram com pena de tirar o menino da casa dele, temendo pela saúde do mesmo. Com o tempo, o avô se recuperou, mas o menino continuou sendo "criado" pelos avós - que, na verdade, moram no mesmo "quintal" da casa dos pais e dos outros irmãos.

A partir desses dados, as alunas passaram a fazer uma série de hipóteses da causa psicogênica do sintoma apresentado, baseando-se nos rudimentos da teoria psicanalítica com que puderam entrar em contato durante o curso: o menino teria sido rejeitado pela mãe, sentir-se-ia excluído do restante da família, estaria no lugar de "salvador do avô" etc. Só que, para surpresa geral, ficaram sabendo que o irmão mais velho dessa criança - cujo histórico 
de nascimento e criação não apresentava, aparentemente, nenhuma semelhança com o do irmão mais novo - já havia frequientado a clínica da faculdade, alguns anos antes, pelo mesmo sintoma. Em entrevistas com os pais, tiveram a notícia de que, na verdade, todos os homens da família - incluindo os tios e primos paternos - apresentavam, em menor ou maior grau, o mesmo sintoma: atraso na aquisição de linguagem. (Inclusive, um quinto filho, nascido após o paciente em questão, também está começando a apresentar o mesmo sintoma). Os pais disseram que, ao comentar o caso com o pediatra, este recomendou que fosse feito um estudo genético do caso. Essa era a demanda das alunas em relação a mim: elas deveriam ou não encaminhar para um estudo genético? Além de mim, elas também consultaram a professora de genética da faculdade que, curiosamente, lhes afirmou não haver relato na literatura de atraso de aquisição de linguagem causado por "herança genética", a não ser em função de alguma síndrome que, entretanto, apresentaria outros sintomas associados mais graves e evidentes. As alunas estavam bastante desconcertadas, já que sua "hipótese ambientalista" havia caído por terra (pois os meninos haviam sido criados em ambientes diferentes) e parecia que a "hipótese inatista" do pediatra também estava se desmoronando... Como explicar o mistério dessa marca que se repetia? Foi muito ilustrativo esse caso, pois na reunião clínica na qual o apresentaram, as alunas puderam se dar conta dessa outra ordem de transmissão. Ao contrário do que pudesse parecer, o fato de esse menino, que era "criado pelos avós", ser também portador dessa marca simbólica (mesmo que sintomática) dos homens da família, longe de excluí-lo, inseria-o nessa série. O sintoma, para além de qualquer "dado ambiental", marcava-o não apenas enquanto sujeito desejante, mas também enquanto "homem". Ou seja, essa marca - cujo histórico desconhecemos nesse caso - pôde ser transmitida para esse menino que, afinal, justamente por ser tomado como filho desse pai, foi suposto como podendo "salvar" o avô.

Por outro lado, também posso testemunhar que, por meio do trabalho que essas alunas realizaram nesse caso, algo do analítico pôde ser transmitido a elas. Por meio de uma tirada chistosa de minha parte, houve um "passede-sentido": na tentativa de relativizar minimamente a crença apaziguadora 
que elas depositavam na genética, relatei para elas um caso de minha própria clínica. Trata-se de um homem de trinta anos, cujo sintoma é "ser médico", profissão na qual ganha muito dinheiro, e que lhe permite sustentar a família num padrão elevado, mas que consome todo o tempo de sua vida e com a qual não se satisfaz, deixando-o extremamente infeliz e angustiado ("um martírio" - como ele diz). Esse homem pertence a uma família de médicos (o pai, o irmão, os tios... - todos médicos). $\mathrm{O}$ interessante é que parece que essa escolha profissional "passou por ele", pois, apesar de que "não iria fazer medicina" desde a adolescência, acabou cumprindo seu "destino oracular" quase sem querer, ou melhor, mesmo não querendo (mas quem sabe desejando?). Bem, o chiste foi quando eu disse para as alunas que iria pedir que esse paciente providenciasse um exame genético (quem sabe não seria encontrado o gene da medicina?).

\section{Para além do sentido, o gozo passa}

Quanto ao desejo de Freud, coloquei-o num nível mais elevado. Eu disse que o campo freudiano da prática analítica permanecia da dependência de certo desejo original que tem sempre papel ambíguo, mas prevalecente na transmissão da psicanálise (...) É também do desejo como objeto que se trata em Freud. (Lacan, 1964/1985)

Os avanços teóricos ocorridos ao longo do ensino de Lacan, sobretudo a partir do conceito de objeto $a$ que ele considera, modestamente, sua única criação na Psicanálise, promoveram uma transformação bastante relevante em relação, exatamente, à questão do objeto da psicanálise e de sua transmissão. No Seminário 11 (Lacan, 1964/1985), dedicado aos quatro conceitos fundamentais da psicanálise (inconscie nte, transferência, pulsão e repetição), Lacan diz que a verdade do sujeito não está nele mesmo, mas num objeto velado por natureza. 
Que Destino Dar à Mensagem Recebida? Apontamentos sobre a Questão da...

A constituição do sujeito é, portanto, retomada em termos de uma topologia. Não pretendo me estender - nos limites desse texto - em relação às consequiências clínicas e teóricas desse avanço conceitual, mas apenas propor alguns possíveis apontamentos iniciais em relação à questão da transmissão, na medida em que a constituição do sujeito pode ser pensada a partir de duas operações lógicas que articulam a relação do sujeito com o Outro: a alienação e a separação.

Em seu texto sobre o tempo lógico, Lacan (1964/1985) enfatiza a urgência do movimento lógico em que o sujeito precipita seu juízo e sua saída, implicando numa tendência ao ato, que evidencia que o sujeito concluiu. Urgência e ato, elementos indissociáveis dessa escolha forçada entre o ser e o sentido, na qual o que Lacan chama de "fator letal" da alienação "faz parir” (separar), ou seja, engendra um sujeito. Em relação a essas operações de alienação e separação, diz-nos Soler (1997, p. 62):

O sujeito da alienação no Seminário 11 não é um sujeito novo (...), é um sujeito que perdeu seu ser e está dividido. O que realmente é novo no Seminário 11 é a introdução da separação. A introdução da alienação é nova somente no nível lógico. (...) A alienação é o destino. Nenhum sujeito falante pode evitar a alienação. É um destino ligado à fala. Mas a separação não é destino. A separação é algo que pode ou não estar presente. (...) A separação requer que o sujeito "queira” se separar da cadeia significante. [Mas há uma condição, no campo do Outro, para que ocorra a separação, já que, aqui, trata-se de um Outro a quem falta alguma coisa] (...) a separação tem uma condição: o encontro com a falta do desejo. (Grifos meus)

Assim, podemos concluir que a inclusão do Nome-do-Pai no campo do Outro - como articulamos a partir da metáfora paterna, tal como desenvolvida no Seminário 5 - descompleta o Outro, evidenciando um limite da própria linguagem, ou seja, do simbólico. Na medida em que Lacan vai se aproximando do conceito de Real, que, a partir desse momento, torna-se fundamental em seu ensino, ele vai cada vez mais sentindo necessidade de utilizar os recursos da lógica formal e da topologia, no sentido de tentar transmitir algo que, exatamente por estar no limite do simbólico, coloca em questão os próprios limites do "transmissível". No entanto, verificamos que é exatamente esse "algo" fora da linguagem (por estrutura) que "passa", com 
a inclusão do Nome-do-Pai, ou seja, a mensagem que o pai porta não é apenas aquela da significação fálica, já que é impossível que essa traduza inteiramente, no nível do significante, aquilo que é da ordem do gozo suposto no Outro. Assim, vemos que, de certo modo, teríamos que rever a hipótese clínica de que o pai de Hans falhou enquanto mensageiro, ou melhor, talvez precisássemos articular que um pai exerce sua função justo ali onde falha. $\mathrm{O}$ que quero dizer é que a "verdadeira" mensagem, digamos assim, é passada ali mesmo onde a significação claudica. O "pai potente" do Seminário 5 começa, então, a vacilar.

\section{Montagem fantasmática: o que se faz com o gozo}

Nessa entidade tão pouco apreendida do corpo, há alguma coisa que se presta a esta operação de estrutura lógica (Lacan, 1966-1967)

As operações de alienação e separação são retomadas de outro modo no Seminário 14 - A Lógica da Fantasia. O conceito de fantasia, tal como Lacan o apresenta, responde a uma questão antiga e polêmica na psicanálise, que é a questão colocada, de outro modo, no início desse trabalho: a possib ilidade de distinção entre realidade e fantasia. O termo phantasie, utilizado por Freud, tem o sentido corrente na língua alemã de "fantasia" ou "imaginação" e só se tornará um conceito a partir de 1897, sendo, portanto, correlato ao conceito de "realidade psíquica" que aparece na obra freudiana na parte E do capítulo VII de "Interpretação dos Sonhos" (Freud, 1900). Freud vinha se debatendo, a partir de sua escuta clínica, com a dualidade entre psíquico e biológico, interno e externo, desde que abandonara a teoria da sedução traumática pela teoria da fantasia inconsciente, fato que aparece de modo bastante explícito em suas cartas a Fliess.

A partir de então, Freud inicia um questionamento a respeito da origem das fantasias que jamais abandonará e que o leva ao conceito de cena primária, fartamente retomado por Lacan neste seminário. Esse mesmo 
questionamento levará os pós-freudianos a criarem o conceito de protofantasia, instituindo uma distinção radical entre mundo interno e externo que sempre mantivera uma tensão na obra freudiana, tensão essa que Lacan se esforçará para superar, respondendo com a lógica da fantasia.

A questão da origem da cena primária é longamente discutida por Freud e, posteriormente, por Lacan, por meio do famoso caso do "Homem dos Lobos": o paciente de Freud recorda-se, durante a análise, que tivera um sonho infantil recorrente, que muito o amedrontava, no qual acordava subitamente e via, através da janela que se abria, sete lobos brancos sobre uma árvore. Os lobos o olhavam fixamente, o que lhe causava horror. A partir daí, o sujeito relata uma cena ainda mais precoce que o próprio sonho, qua ndo teria despertado e presenciado um coito a tergo dos pais. A cena, que teria sido vista pelo menino por volta de um ano e meio de idade, teria sido reativada na época do sonho, por volta dos quatro anos, devido às questões relativas a descoberta das diferenças sexuais e à realidade da castração. A reflexão freudiana, no entanto, vai além, já que ele questiona se as cenas infantis não seriam, elas mesmas, construções em análise. Além disso, Freud ainda introduz a possibilidade de essa construção apoiar-se em lembranças distorcidas da visão do coito de animais.

Se Freud fica emaranhado na teia de possibilidades a respeito da realidade ou não da cena primária, Lacan, por sua vez, atravessa essa questão no Seminário 14, com a noção de verdade:

a associação livre nos conduz sobre o plano da estrutura de rede em uma dimensão que não é a realidade, mas a VERDADE. [E acrescenta] No caso do homem dos lobos a pergunta sobre a verdade da cena não se reduz à questão de saber se sim ou não. O essencial é saber de que modo o sujeito pode articular essa cena em significantes, quer dizer verificá-la em todo seu ser e por seu sintoma. ${ }^{3}$ (Lacan, 19661967, aula de 23 de novembro de 1966)

3 A tradução e os grifos são meus. 
Por meio do caso do "Homem dos Lobos", então, Lacan oferece encaminhamentos inéditos para questões crucias em relação à fantasia:

1) A fantasia se trata de uma montagem, uma operação de linguagem que mostra, ao mesmo tempo, o assujeitamento e a produção própria do sujeito. Essa montagem pertence aos registros do simbólico e do imaginário, pois o real, Lacan nos diz, só é entrevis to quando a máscara do fantasma vacila.

2) O complexo de castração é o ordenador da cena de sedução e da cena primária, que se articulam no complexo de Édipo.

Não há, portanto, realidade material, a não ser o significante. Lacan tenta dar conta dessa montagem desde o esquema L, também chamado de "esquema da dialética intersubjetiva", momento em que ele está tentando articular como a encenação imaginária é sustentada pelo simbólico. Aí, Lacan tentava articular o que chamou, no Seminário sobre a carta roubada de "programa através do qual uma linguagem formal funda um sujeito. [E acrescenta] (...) tal programa não é simples, já que supõe que um sujeito só o cumprirá colocando, aí, algo de si” (Lacan,1955/1998, p. 47). A cena fantasmática remete, portanto, à Outra cena inconsciente, que nunca terá sido anterior ao significante, pois é, ela própria, efeito de significante.

Entretanto, do lado mesmo da produção desse sujeito efeito de linguagem, encontra-se o objeto $a$. Como Lacan (1960/1998) já havia trabalhado fartamente no texto "Subversão do Sujeito e Dialética do Desejo", a falta do Outro é tomada pelo neurótico como demanda, ou seja, como uma mensagem dirigida a ele e em relação a qual ele responde com a função do objeto em sua fantasia, articulando, aí, a pulsão; assim, a fantasia não é apenas uma montagem gramatical, mas também uma montagem pulsional, sendo o próprio sujeito engendrado enquanto objeto. Daí o duplo aspecto do fantasma: um alcançável pela linguagem e outro, radicalmente estranho à linguagem. O fantasma fixa, portanto, a libido, tentando recuperar o gozo perdido. Retomo um ponto essencial recuperado por Luiz Carlos Nogueira, em sua a- 
presentação sobre o Seminário 11, no Fórum do Campo Lacaniano, enfatizando a afirmação de Lacan de que a experiência primordial da falta para o sujeito diz respeito à possibilidade de sua própria perda: pode o Outro me perder? Daí, deduz-se que o $a$ do fantasma é o próprio sujeito - ou, como formula Lacan em "A Ciência e a Verdade", "o sujeito está em exclusão íntima de seu objeto" (1966/1998, p. 869).

Deste modo, verifica-se que, cada vez mais, o ensino de Lacan oferece um estatuto lógico à falta do Outro e destaca como o sujeito recebe a transmissão dessa falta, ou seja, desse limite ao gozo. No Seminário 14, o $\mathrm{S}(\mathbb{A})$ (significante do Grande Outro barrado) ao qual o fantasma é uma resposta, é definido como "falha no universo do discurso". Isso quer dizer que não há significante que possa significar-se a si mesmo. Assim, dizer que não há Outro é dizer que não há nenhum lugar onde se assegurar a verdade constituída pela palavra. É a partir daí que se pode entender a repetição como a busca de se repetir exatamente aquilo que escapa, pois é exatamente a marca perdida que provoca a repetição buscada, como exemplifica Lacan: se um livro pudesse conter todos os livros, ele mesmo ficaria fora desse catálogo, e assim sucessivamente. É a essa falta radical de referente que o objeto $a$ vem responder.

\section{Potência de criação: fazer outra ficção do real}

O saber é coisa que se diz, que é dita. Pois bem, o saber fala por conta própria - eis o inconsciente (Lacan, 1969-1970/1991)

O avanço teórico mais significativo oferecido por Lacan, no que se refere àquilo que se transmite para além do simbólico, ocorre no Seminário 17 - O Avesso da Psicanálise (1969-1970/1991). O que pretendo indicar, nos limites desse trabalho, são apenas questões que me ocorreram a partir de sua leitura e a partir das quais pretendo encaminhar minha pesquisa atual. 
Logo no início do Seminário, Lacan explicita que, embora tudo seja estrutura, nem tudo é linguagem - deixando claro, entretanto, que não se pode prescindir dela. Em relação à afirmação de que se trata de um discurso sem palavras, adverte:

é que sem palavras, na verdade, ele pode muito bem subsistir. Subsiste em certas relações fundamentais. Estas, literalmente, não poderiam se manter sem a linguagem. Mediante o instrumento da linguagem instaura-se um certo número de relações estáveis, no interior das quais certamente pode inscrever-se algo bem mais amplo, que vai bem mais longe do que as enunciações efetivas. (Lacan, 19691970/1991, p. 11, grifos meus)

Vemos, portanto, que o que está além, nesse momento não é um "outro sentido" ou um "sentido oculto" ou um "sentido a mais" e sim, justame nte, o que remete ao "sem sentido" (pas de sens). Aliás, Lacan dirá, em relação ao "verdadeiro sentido", que ele remete, pela insistência, à dimensão da verdade - que, como vimos, ele já vinha trabalhando, de outro modo, desde o Seminário 14.

A verdade nunca pode ser toda-dita e, nesse sentido, há uma impotência do lado do pai:

de acordo com o que enunciei sobre o pai - porque não partir do fato de que o pai de Dora, ponto pivô de toda aventura, ou desventura, é propriamente um homem castrado? (...) considerá-lo como deficiente em relação a uma função com a qual não se ocupou é dar-lhe, falando propriamente, uma destinação simbólica. (p. 88)

Ou seja, ao contrário do "pai potente", proposto no Seminário 5, aqui Lacan articula que, é justamente onde há um déficit (quer dizer, na deficiência), é que o pai exerce sua função simbólica de transmissão, não somente de um sentido, mas sobretudo de uma verdade "não toda", na medida em que o saber representa um limite ao gozo do Outro (aquém/além da linguagem).

A potência de que se trata, no Seminário 17, longe de ser uma potência fálica, é o que Lacan chama de "potência de criação". Esse é um ponto que merece, certamente, ser mais bem explorado. 
Que Destino Dar à Mensagem Recebida? Apontamentos sobre a Questão da...

Em todo caso, interessa realçar, aqui, a relação que Lacan estabelece entre o pai morto

que só se alcança a partir de um lugar vazio e sem comunicação - e o gozo como impossível: que o pai morto seja o gozo, isto se apresenta a nós como sinal do próprio impossível (...) aí reconhecemos, com efeito, para além do mito do Édipo, um operador estrutural que coloca no centro da enunciação de Freud um termo do impossível. (1969-1970/1991, p. 116)

Ainda em relação a esse limite imposto pela linguagem - e da própria linguagem -, Lacan dirá: "a criação repetitiva poderia também partir de uma impotência original (...) Se pudermos perceber que a criança é o pai do homem, certamente deve haver alguma coisa que faz mediação, que é precisamente a instância do mestre..." (1969-1970/1991, p. 117).

A questão que permanece para mim, portanto, é a seguinte: qual a especificidade do discurso do analista no que diz respeito ao "tratamento possível" para o "impossível" do gozo? E ainda: quais as condições de transmissão desse discurso que possibilitem a criação de um saber no lugar da verdade? Temos alguns indícios: quanto à análise, Lacan nos diz que recorrer ao não-todo, aos impasses da lógica, é mostrar a saída fora das ficções de mundanidade, fazer outra ficção do real.

Prates, A. L. (2004). The received message: where to lead it? (Notes on the issue of transmission in Psychoanalysis). Psicologia USP, 15(1/2), 149167.

\begin{abstract}
This paper introduces the specificity of the concept of transmission in Psychoanalysis, especially from Jacques Lacan's proposition that "the unconscious is structured as a language". It develops the idea introduced by this author in the 50's which considers human subjective constitution a result of the symbolic law transmission mediated by the father, further developed in the concepts of "father metaphor" and "Name of the Father". It analyses the theoretical-clinical consequences to the issue of transmission promoted by the object "a" concept, especially in regard to the jouissance external to language and the fantasy construction. It
\end{abstract}




\section{Ana Laura Prates}

also highlights the significant advances of the Psychoanalysis Upside-Down seminar related to what is transmitted beyond the symbolic, from the articulation between the conceptual notion of the discourse without words and the inability of knowledge to apprehend the whole truth. Finally, it proposes that the idea of "creative spark" replaces the "paternal metaphor" of the 50's, revealing clinical developments for the analysis termination debate.

Index terms: Psychoanalysis. Transmission. Metaphor. Jouissance. Lacan, Jacques, 1901-1981.

Prates, A. L. (2004). Que Faire Du Message Reçu? (Notations Sur La Transmission En Psychanalise). Psicologia USP, 15(1/2), 149-167.

Résumé: Dans cet article on présente la specificité du concept de transmission en Psychanalyse, surtout à partir de la proposition de Jacques Lacan selon laquelle "l'inconscient est structuré comme un langage". On y développe l'idée présentée par Lacan aux années 50 selon laquelle la constitution subjective humaine est issue d'une expérience de transmission de la loi symbolique à travers la médiation paternelle, ce qui développera les concepts de Métaphore paternelle et Nom-du-père. On y analise les conséquences théorique-cliniques du concept d'objet 'a' pour la question de la transmission, surtout en ce qui concerne la juissance hors le langage et la construction fantasmatique. On y traite aussi sur l'avancée significative que le séminaire "L'envers de psychanalyse" offre en ce qui concerne ce qui est transmis au-delà du symbolique, à partir de l'articulation de la notion conceptuelle du discours sans mots e de l'impuissance du savoir à embrasser toute la vérité. Enfin, on y propose que l'idée de puissance de la création remplace l'idée de la puissance du père des années 50 tout en dévoilant des développements cliniques pour le débat sur la fin d'une analyse.

Mots-clés: Psychanalyse. Transmission. Métaphore. Jouissance. Lacan, Jacques, 1901-1981. 
Que Destino Dar à Mensagem Recebida? Apontamentos sobre a Questão da...

\section{Referências}

Houaiss, A. (2001). Dicionário Houaiss da língua portuguesa. Rio de Janeiro : Objetiva.

Lacan, J. (1966-1967). Seminario 14. La lógica del fantasma. Versão não estabelecida.

Lacan, J. (1985). O Seminário. Livro 11: Os quatro conceitos fundamentais da Psicanálise. Rio de Janeiro: Jorge Zahar. (Trabalho original publicado em 1964)

Lacan, J. (1991). O Seminário. Livro 17: O avesso da Psicanálise. Rio de Janeiro: Jorge Zahar. (Trabalho original publicado em 1969-1970)

Lacan, J. (1998). A ciência e a verdade. In J. Lacan, Escritos (pp. 869-892). Rio de Janeiro: Jorge Zahar. (Trabalho original publicado em 1966)

Lacan, J. (1998). De uma questão preliminar a todo tratamento possível da psicose. In J. Lacan, Escritos (pp. 537-590). Rio de Janeiro: Jorge Zahar. (Trabalho original publicado em 1956)

Lacan, J. (1998). Seminário sobre a carta roubada. In J. Lacan, Escritos (pp. 13-66). Rio de Janeiro: Jorge Zahar. (Trabalho original publicado em 1955)

Lacan, J. (1998). Subversão do sujeito e a dialética do desejo. In J. Lacan, Escritos (pp. 807-842). Rio de Janeiro: Jorge Zahar. (Trabalho original publicado em 1960)

Lacan, J. (1999). O Seminário. Livro 4: A relação de objeto. Rio de Janeiro: Jorge Zahar. (Trabalho original publicado em 1956-1957)

Lacan, J. (1999). O Seminário. Livro 5: As formações do inconsciente. Rio de Janeiro: Jorge Zahar. (Trabalho original publicado em 1957-1958)

Porge, E. (1994). Os Nomes do Pai em Jacques Lacan. Rio de Janeiro: Companhia de Freud. (Trabalho original publicado em 1989)

Quinet, A. (1997). Teoria e clínica das psicoses. Rio de Janeiro: Forense Universitária.

Semprun, J. (1995). A escrita ou a vida. São Paulo: Companhia das Letras.

Soler, C. (1997). O sujeito e o Outro II. In R. Feldstein, B. Fink, \& M. Jaanus (Orgs.), Para ler o seminário 11 de Lacan. Rio de Janeiro: Jorge Zahar.

Recebido em 09.06.2004

Aceito em 06.08.2004 